\title{
PSYCHOMETRIC PROPERTIES OF THE 25-ITEM CONNOR-DAVISON RESILIENCE SCALE: PRELIMINARY DATA FOR A ROMANIAN MILITARY POPULATION
}

\author{
Iulia-Clarisa GIURC $\breve{A}$ \\ “Babeș-Bolyai” University, Cluj-Napoca, Romania \\ clarisagiurca@yahoo.com
}

Adriana BABAN

“Babeș-Bolyai” University, Cluj-Napoca, Romania adrianababan@psychology.ro

Sebastian PINTEA "Babeș-Bolyai" University, Cluj-Napoca, Romania sebastianpintea@psychology.ro

Bianca MACAVEI

"Babeș-Bolyai” University, Cluj-Napoca, Romania biancamacavei@gmail.com

\begin{abstract}
The following study is aimed at investigating the construct validity of the 25-item Connor-Davidson Resilience Scale (CD-RISC 25) on a Romanian military population. The exploratory factor analysis was conducted on 434 male military participants, aged between 24 and 50 years $(M=34.83$, S.D. $=6.14)$ and the confirmatory factor analysis was conducted on a sample of 679 military participants, of 605 men and 74 women, aged between 18 and 59 years $(M=38.37$, S.D. $=9.07)$. Factor analysis of the scale showed it to be a bidimensional, rather than a multidimensional instrument, as the original five-factor structure was not replicated in this military Romanian sample. Moreover, EFAs suggested that a 14-item bidimensional model should be retained and CFA confirmed that this model fit the data best.
\end{abstract}

KEYWORDS: resilience, soldiers, EFA and CFI

\section{Introduction}

The construct of resilience describes "the ability of individuals to adapt to various adverse conditions, while maintaining their meaning, balance, mental, and physical well-being" (Sergeant \& Laws-Chapman, 2012). Resilience is defined as "the sum of psychological characteristics that promote positive adaptation when facing stressful and adverse events, problems, adversities, or conflicts" (Luthans, 2002; Wagnild, 2003). It is often stated that you do not have to be born resilient because it is a capacity which can be built, a characteristic which leads to progress and increased responsibility (Youssef \& Luthans, 2007). 
In a previous research on the degree of malleability and educability of KSAO's (knowledge, skills, abilities, and others) specifics to military leaders, MuellerHanson, White, Dorsey, and Pulakos (2005) stated that resilience is so stable and resistant to change like a personality trait.

Many studies regarding psychological resilience have proposed distinct resiliency models (Richardson, 2002; Richardson, Neiger, Jensen \& Kumpfer, 1990) and, in the course of time, various instruments were designed to measure it. Connor and Davidson developed in 2003 a new scale to assess psychological resilience called "Connor-Davidson Resilience Scale CD-RISC" (Connor \& Davidson, 2003). This instrument has been gaining recognition among resilience researchers because of the reliability and validity of the scale and its applicability in diverse populations (Manzano-Garcia \& Calvo, 2013).

CD-RISC scale is a self-rating instrument with 25 items, designed to measure "a respondent's stress coping ability by tapping various features of resilience" (Connor \& Davidson, 2003). When it was initially proposed by Connor and Davidson, the scale generated a resilience score based on five factors: "personal competence, high standards, and tenacity", "trust in one's instincts, tolerance of negative affect, and strengthening the effects of stress", "positive acceptance of change and secure relationships", "control" and "spiritual influences".

Taking into consideration that resilience is "a multidimensional variable that changes in different populations with diverse living conditions, cultural background and sociodemographic characteristics" (Wu, Tan \& Liu, 2017), a number of studies supported the initial factorial structure (Jung et al, 2012; Yu, Lau, Mak, Zhang \& Lui, 2011) while others did not.

The studies that failed to support the initial 5-factor framework of CD-RISC 25, proposed their own factorial analytic structure that fit in a particular country (Jorgensen \& Seedat, 2008; ManzanoGarcia \& Calvo, 2013; Mealer, Schmiege \& Meek, 2016; Yu \& Zhang, 2007).

For instance, in a Chinese community sample, Yu, Lau, Mak, Zhang, and Lui (2011) yielded a 3-factor structure for CD-RISC. Faria Anjos, Heitor dos Santos, Ribeiro, and Moreira (2019) also suggested a 3-factor solution for a Portuguese sample, while Velickovic, Rahm, Hallberg, Axelsson, Borrebaeck, Ryden, Johnsson \& Mansson (2020) recommended that in a Swedish context CD-RISC be applied as a one-dimensional scale.

McGillivray and Ho (2016) implied argued that the original scale analytic structure was not supported in a Thai population and proposed a new 3-factor structure. They underlined that Thai population lure their resilience from "their perception of personal competence and their ability to tolerate unpleasant emotions", "their belief in the availability of and successful access to support resources", and "their confidence in their ability to influence the situation".

Psychometric evaluation of CD-RISC 25 was conducted on soldiers too. Considering a military sample from China, Xie, Peng, Zuo, and Li (2016) proposed a 3-factor structure and, analysing a big sample of U.S. veterans, Green, Hayward, Williams, Dennis, Bryan, Taber, Davidson, Beckham, and Calhoun (2014) found a 2 -factor structure for this scale.

These findings indicate that the CD-RISC 25 scale can be studied and improved in order to meet the specific traits of the military population in Romania. Therefore, starting from the hypothesis as the initially released factor structure may not be adequate for our military sample, we have conducted a statistical analysis to identify the factorial model of CD-RISC 25 that complies with the data. 


\section{Aim}

The present research aim is to investigate the construct validity of the CD-RISC 25 on a Romanian military population. In order to identify an adequate tool to assess psychological resilience in this specific population, we have focused to determine the proper factorial framework of CD-RISC. Therefore, we administered the scale to review its reliability and validity by a confirmatory factor analyse in the specific population.

\section{Method}

\subsection{Participants \& Procedure}

The CD-RISC 25 scale was bought from Connor and Davison and was delivered in Romanian language, so it did not need translation. This questionnaire was administrated to active-duty military personnel between 2015 and 2018 . Data collection was part of a larger survey on protective factors of resilience. Participants were asked to fill in the test battery, consisting of several parts. Each soldier gave his or her written consent to participate in this research and agreed to allow the researcher to use the results in scientific interest.

A sample of 434 male military participants, aged between 24 and 50 years $(\mathrm{M}=34.83$, S.D. $=6.14)$ were used to conduct the exploratory factor analysis.

A sample of 679 military participants, of which 605 men and 74 women, aged between 18 and 59 years $(\mathrm{M}=38.37$, S.D. $=9.07)$ were used to carry out the confirmatory factor analysis.

\subsection{Measures}

The Connor-Davison Resilience Scale was designed to measure resilience, conceptualized as "the accumulation of personal qualities that allow an individual to successfully cope with adverse situations" (Connor \& Davidson, 2003). The instrument contains 25 items, rated by the participants on a five-point Likert scale.

\subsection{Methodology}

Participants' responses to the CD-RISC 25 scale were subjected to five exploratory factor analysis limited to six, five, four, three, and two factors, with oblique rotation.

The results obtained on the data set suggested that the output did not replicate the original results. The factor design for the six-factor, five-factor, and four-factor solutions did not hold (Bender \& Chou, 1987; Comrey \& Lee, 2009; Costello \& Osborne, 2005; DiStefano, Zhu \& Mindrila, 2009) and for the three-factor and two-factor solutions, certain items showed low communalities, low loadings and cross-loadings (Hayton, Allen \& Scarpello, 2004; Ledesma \& Valero-Mora, 2007).

The qualitative analysis of the items led to the elimination of 9 items from the questionnaire. Their loading and communality in the model supported this decision. Item 3 and item 9, belonging in the original scale to the factor "spiritual influence", were eliminated because they have a negative estimated variance within the model.

Another EFA limited to two factors with oblique rotation, for the remaining 14 items, was then conducted to clarify the factorial structure of CD-RISC.

Factor 1 explains $45.16 \%$ of the variance, with an eigenvalue of 6.32 , and factor $2,7.97 \%$ of the variance, with an eigenvalue of 1.12 . The two-factor solution explains $53.13 \%$ of the total variance in the data.

It can be noticed that Factor 1 is closely related to the items that reflect a person's conviction in his ability to mobilize the cognitive and motivational resources necessary to successfully perform the given tasks or anticipation of positive results in actions taken due to knowledge and skills. For these reasons, Factor 1 could be labelled as "self-efficacy and perseverance in the face of challenges". The items of the second factor have in 
common the fact that they refer to the ability to make solid, legitimate decisions in a short time, especially in times of crisis and uncertainty, so it could be labelled as "decision making skills in risk situations". The factor loadings are shown in Table no. 1.

Table no. 1

Factor Loadings from the EFA

\begin{tabular}{lccc}
\hline & \multicolumn{2}{c}{ Factor loading } & \\
\cline { 2 - 3 } Variable & 1 & 2 & Communality \\
\hline 1. Adapt when changes occur & 0.66 & & 0.41 \\
4. Deal with everything & 0.75 & & 0.58 \\
5. Past success gives confidence & 0.73 & & 0.57 \\
8. Bounce back & 0.81 & & 0.63 \\
10. Best effort & 0.57 & & 0.31 \\
11. Achieve my goals & 0.83 & & 0.71 \\
12. Even when hopeless do not give up & 0.75 & & 0.61 \\
14. Under pressure stay focused & 0.84 & & 0.71 \\
15. Prefer to take lead & & 0.58 & 0.39 \\
16. Not easily discouraged & 0.77 & & 0.57 \\
17. Think of myself as strong person & 0.80 & & 0.66 \\
18. Make unpopular decisions & & 0.57 & 0.38 \\
19. Handle unpleasant feelings & 0.75 & & 0.56 \\
20. Act on hunch & & 0.66 & 0.39 \\
\hline
\end{tabular}

Note: Factor loadings $<.32$ are suppressed.

Confirmatory factor analysis

A CFA was performed on sample $2(\mathrm{n}=679)$ in order to test the bidimensional model with 14 -items.
The results of the CFA model are presented in Table no. 2, the correlations between the latent variables are shown in Table no. 3 and the node diagram in Figure no. 1.

Table no. 2

Unstandardized Loadings, Standardized Loadings, and Significance Levels for Each Parameter in the CFA Model $(N=679)$

\begin{tabular}{lllc}
\hline \multicolumn{1}{c}{ Parameter Estimate } & Unstandardized & Standardized & $p$ \\
\hline Covariance for Factor_1 and Factor_2 & $0.09(0.01)$ & 0.57 & $<.001$ \\
Error in Factor_1 & $0.19(0.02)$ & 1.00 & $<.001$ \\
Error in Item_1 & $0.18(0.01)$ & 0.48 & $<.001$ \\
Error in Item_4 & $0.18(0.01)$ & 0.40 & $<.001$ \\
Error in Item_5 & $0.20(0.01)$ & 0.46 & $<.001$ \\
Error in Item_8 & $0.17(0.01)$ & 0.40 & $<.001$ \\
Error in Item_10 & $0.43(0.02)$ & 0.69 & $<.001$ \\
Error in Item_11 & $0.10(0.01)$ & 0.26 & $<.001$ \\
Error in Item_12 & $0.22(0.01)$ & 0.46 & $<.001$ \\
Error in Item_14 & $0.15(0.01)$ & 0.40 & $<.001$
\end{tabular}




\begin{tabular}{lccc}
\hline \multicolumn{1}{c}{ Parameter Estimate } & Unstandardized & Standardized & $p$ \\
\hline Error in Item_16 & $0.23(0.01)$ & 0.50 & $<.001$ \\
Error in Item_17 & $0.14(0.01)$ & 0.37 & $<.001$ \\
Error in Item_19 & $0.22(0.01)$ & 0.47 & $<.001$ \\
Error in Factor_2 & $0.12(0.03)$ & 1.00 & $<.001$ \\
Error in Item_20 & $0.98(0.06)$ & 0.89 & $<.001$ \\
Error in Item_15 & $0.37(0.05)$ & 0.44 & $<.001$ \\
Error in Item_18 & $0.94(0.07)$ & 0.66 & $<.001$ \\
\hline
\end{tabular}

Note. $\chi^{2}(76)=235.71, p<.001$;

Table no. 3

Correlation Table for the Latent Variables

\begin{tabular}{|l|l|l|}
\hline Variable & Factor_1 & Factor_2 \\
\hline Factor_1 & 1.00 & -- \\
\hline Factor_2 & 0.57 & 1.00 \\
\hline
\end{tabular}

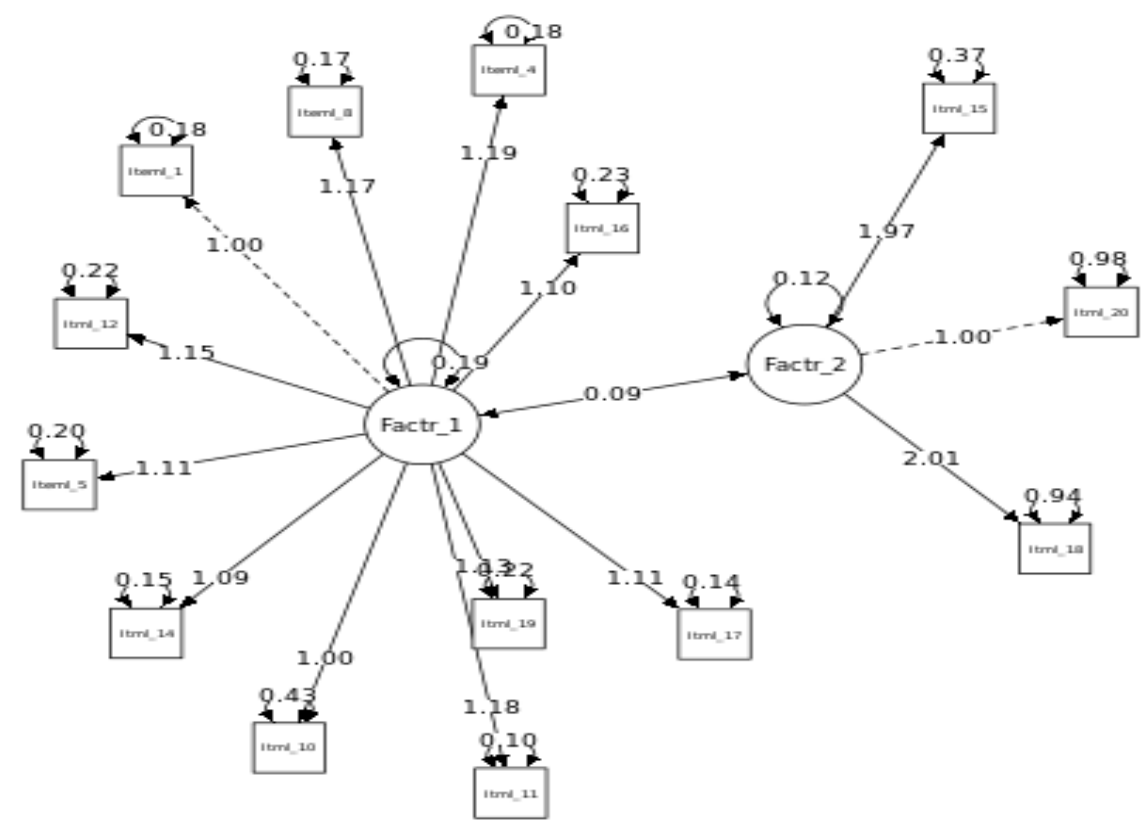

Figure no. 1: Node diagram

Even though the $\chi^{2}$ is significant $\left(\chi^{2}(76)=235.71, p<.001\right)$, both absolute and relative fit indices suggested that a two-factor model fits the data well $(\mathrm{NF} 1=0.95 ; \mathrm{TLI}=0.96$; $\mathrm{RMSEA}=0.06$, SRMR $=0.04, \mathrm{CFI}=0.97)$ (Hooper, Coughlan \& Mullen, 2008).

The results of the CFA thus support the model obtained in the last EFA. Internal consistency of the 14-items CD-RISC was high $(\alpha=.91)$.

\section{Discussion}

The present research aim is to investigate the construct validity of the CD-RISC 25 on a Romanian military population. Current results revealed that this scale is a reliable psychometric instrument for assessing resilience, with high internal consistency that can be applied to a military population.

The primary five-factor framework was not reiterated in this Romanian military sample. Data showed that CD-RISC is a 
bidimensional, rather than a multidimensional instrument for this particular population. Moreover, a bidimensional model with 14-items was suggested by EFAs to be retained. Furthermore, CFA confirmed that this bidimensional framework fits the data well.

The EFAs run in of this study suggest that items $3,6,7,9,13,21,22,23,24$, and 25 are not part of the resilience construct. In the initial version of CD-RISC 25 scale, the $3^{\text {rd }}$ and $9^{\text {th }}$ items make up the "spiritual influence" factor and items, 13, 21 and 22 make up the "control" factor. As the results show, for military personnel from Romania, spiritual influences and control, as they are conceptualized by Connor and Davison, are not structural components of resilience.

We should also note that $72 \%$ of all respondents to this study say that the statement "When there are no clear solutions to my problems, sometimes fate or God can help me" is completely untrue or rarely true for them.

These results are in accordance with several studies of psychometric properties of CD-RISC 25. Some researches show that the factorial design of CD-RISC varies depending on the cultural context of the population studied (Ionescu, 2013) and the five-facture framework of CD-RISC 25 does not replicate in different contexts (Velickovic et al., 2020).

For example, in a Sweden sample, the authors showed that the remaining model excluded 3 items, items 3 and 9 that form the "spiritual influences" from the initial model (Velickovic et al., 2020). Similar decisions were made by researchers from Australia and Spain, where their final model did not include all items from the original model (Burns \& Anstey, 2010; González, Sierra, Martínez \& MartinezMolina, 2015).

$\mathrm{Yu}$ and Zhang (2007) underlined also that in their sample, the spirituality dimension is not a factor of resilience, as presented by its authors.
Based on a research conducted in Iran, Khoshouei (2009) highlights a factorial structure with 4 factors, namely: "motivation", "self-confidence", "tenacity", and "adaptability", without the dimension of "spirituality".

In a research conducted on South Africans, Jorgensen and Seedat (2008) also highlight a factorial structure, different from that described by Connor and Davison (2003), composed of three dimensions: tenacity, adaptation, and spirituality.

From this perspective, our paper contributes to the existing information in specialized publications by revealing the importance of cultural aspects in measuring resilience.

\section{Limitations}

The current results must be interpreted bearing in mind certain limitations. First, we used a convenience sample that cannot be considered representative of the entire military population.

Second, in our study, there is an unequal distribution of the participants 'gender. The fact that the sample was composed of a significantly larger number of men compared to women, may have influenced the final results. Future research should take these limitations into consideration so that the results obtained are of greater relevance to science.

\section{Conclusions}

The results show that in our specific military sample from Romania, CD-RISC is a valid bidimensional scale, composed by 14-items. The scale produced a total score of resilience based on two factors: "selfefficacy and perseverance in the face of challenges" and "decision making skills in risk situations".

Furthermore, this study underlines the idea that "spiritual influence" and "control", as Connor and Davison (2015) defined them are not part of the resilience construct. 
This fact could be explained by the socioprofessional context of military life or by the amplitude constraints of the factors. Future studies should investigate this further.
Yet another direction of research could be a study aimed at elucidating whether spirituality does have an impact on resilience in a military context.

\section{REFERENCES}

Arias González, V.B., Crespo Sierra, M.T., Arias Martínez, B., Martínez-Molina, A. \& Ponce, F.P. (2015). An in-depth psychometric analysis of the Connor-Davidson resilience scale: calibration with Rasch-Andrich model. Health Qual Life Outcomes, Vol. 13. https://doi.org/10.1186/s12955-015-0345-y.

Bender, P.M., \& Chou, C.P. (1987). Practical issues in structural modeling. Sociological Methods \& Research, Vol. 16, Issue 1, 78-117.

Burns, R.A., \& Anstey, K.J. (2010). The Connor-Davidson resilience scale (CD-RISC): testing the invariance of a uni-dimensional resilience measure that is independent of positive and negative affect. Personality and Individual Differences, Vol.48, Issue 5, 527-531.

Comrey, A.L., \& Lee, H.B. (2009). A first course in factor analysis (2 ${ }^{\text {nd }}$ Edition). New York: Psychology Press.

Connor, K.M., \& Davidson, J.R.T. (2003). Development of a New Resilience Scale: The Connor-Davidson Resilience Scale (CDRISC). Depression and Anxiety, Vol. 18, Issue 2, 76-82.

Costello, A.B., \& Osborne, J.W. (2005). Best practices in exploratory factor analysis: four recommendations for getting the most from your analysis. Practical assessment, Research \& Evaluation, Vol. 10. DOI: https://doi.org/10.7275/jyj1-4868

DiStefano, C., Zhu, M., \& Mindrila, D. (2009). Understanding and using factor scores: Considerations for the applied researcher. Practical Assessment, Research \& Evaluation, Vo. 14, Issue 20, 1-11.

Faria Anjos, J., Heitor dos Santos, M.J., Ribeiro, M.T., \& Moreira, S. (2019). ConnorDavidson Resilience Scale: validation study in a Portuguese sample. BMJ Open, Vol. 9, Issue 6. DOI: $10.1136 /$ bmjopen-2018-026836

Green, K.T., Hayward, L.C., Williams, A.M., Dennis, P.A., Bryan, B.C., Taber, K.H., Davidson, J.R.T., Beckham, J.C., \& Calhoun, P.S. (2014). Examining the Factor Structure of the Connor - Davidson Resilience Scale (CD-RISC) in a Post-9/11 U.S. Military Veteran Sample. Assessment, Vol. 21, Issue 4, 443-451. https://doi.org/10.1177/1073191114524014

Hayton, J.C., Allen, D.G., \& Scarpello, V. (2004). Factor retention decisions in exploratory factor analysis: A tutorial on parallel analysis. Organizational Research Methods, Vol. 7, Issue 2, 191-205.

Hooper, D., Coughlan, J., \& Mullen, M. (2008). Structural equation modelling: Guidelines for determining model fit. Electronic Journal of Business Research Methods, Vol. 6, Issue 1, 53-60.

Ionescu, Ș. (2013). Tratat de reziliență asistată. Bucharest: Editura Trei.

Jorgensen, I.E., \& Seedat, S. (2008). Factor structure of the Connor-Davidson Resilience Scale in South African adolescents. International Journal of Adolescent Medicine and Health, Vol. 20, Issue 1, 23-32.

Jung, Y.E., Min, J.A., Shin, A.Y., Han, S.Y., Lee, K.U., Kim, T.S., Park, J.E., Choi, S.W., Lee, S.H., Choi, K.S., Park, Y.M., Woo, J.M., Bhang, S.Y., Kang, E.H., Kim, W., Yu, J.J., \& Chae, J.H. (2012). Positiveness research team of Korea the Korean version of the Connor-Davidson Resilience Scale: an extended validation. Stress Health., Vol. 28, Issue 4, 319-326. 
Khoshouei, M.S. (2009). Psychometric evaluation of the Connor-Davidson Resilience Scale (CD-RISC) using Iranian students. International Journal of Testing, Vol. 9, Issue 1, 60-66. https://doi.org/10.1080/15305050902733471

Ledesma, R.D., \& Valero-Mora, P. (2007). Determining the number of factors to retain in EFA: An easy-to-use computer program for carrying out parallel analysis. Practical Assessment, Research \& Evaluation, Vol. 12, Issue 2, 1-11.

Luthans, F. (2002). The need for and meaning of positive organizational behavior. Journal of Organizational Behavior, Vol. 23, Issue 6, 695-706.

Manzano-Garcia, G., \& Calvo, J.C.A. (2013). Psychometric properties of ConnorDavidson Resilience Scale in a Spanish sample of entrepreneurs. Psicothema, Vol. 25, Issue 2, 245-251.

McGillivray, K. \& Ho, R. (2016). Validation of the Connor Davidson Resilience Scale (CD-RISC) as applied within the Thai context. Scholar: Human Scriences, Vol. 8, Issue 2, 178-188.

Mealer, M., Schmiege, S.J., \& Meek, P. (2016). The Connor-Davidson Resilience Scale in Critical Care Nurses: A Psychometric Analysis. Journal of Nursing Measurement, Vol. 24, Issue 1, 28-39.

Mueller-Hanson, R.A., White, S.S., Dorsey, D.M., \& Pulakos, E.D. (2005). Training Adaptable Leaders: Lessons from Research and Practice, Arlington, Va.: U.S. Army Research Institute for the Behavioral and Social Sciences, Research Report 1844.

Richardson, G.E. (2002). The metatheory of resilience and resiliency. Journal of Clinical Psychology, Vol. 58, Issue 3, 307-321.

Richardson, G.E., Neiger, B.L., Jensen, S., \& Kumpfer, K.L. (1990). The resiliency model. Health Education, Vol. 21, Issue 6, 33-39.

Sergeant, J., \& Laws-Chapman, C. (2012). Creating a positive workplace culture. Nursing Management, Vol. 18, Issue 9, 14-19.

Velickovic, K., Rahm Hallberg, I., Axelsson, U., Borrebaeck, C.A.K, Ryden, L., Johnsson, P., \& Mansson, J. (2020). Psychometric properties of the Connor-Davidson Resilience Scale (CD-RISC) in a non-clinical population in Sweden. Health and Quality of Life Outcomes, Vol. 18, Issue 1, 132. https://doi.org/1 0.1186/s12955-020-01383-3

Wagnild, Gail. (2003). Resilience and Successful Aging: Comparison Among Low and High Income Older Adults. Journal of gerontological nursing, Vol. 29, 42-9. 10.3928/00989134-20031201-09.

Wu, L., Tan, Y., \& Liu, Y. (2017). Factor structure and psychometric evaluation of the Connor-Davidson resilience scale in a new employee population of China. BMC Psychiatry, Vol. 17, 49. https://doi.org/10.1186/s12888-017-1219-0

Xie, Y., Peng, L., Zuo, X., \& Li, M. (2016). The Psychometric Evaluation of the Connor- Davidson Resilience Scale Using a Chinese Military Sample. PLoS ONE, Vol. 11, Issue 2. https://doi.org/10.1371/journal.pone.0148843

Youssef, C.M., \& Luthans, F. (2007). Positive Organizational Behavior in the Workplace: The Impact of Hope, Optimism, and Resilience. Journal of Management, Vol. 33, Issue 5, 774-800.

Yu, X., \& Zhang, J. (2007). Factor analysis and psychometric evaluation of the ConnorDavidson Resilience Scale (CD-RISC) with Chinese people. Social Behavior and Personality, Vol. 35, Issue 1, 19-30.

Yu, X.N., Lau, J.T., Mak, W.W., Zhang J., \& Lui, W.W. (2011). Factor structure and psychometric properties of the Connor-Davidson resilience scale among Chinese adolescents. Comprehensive Psychiatry, Vol. 52, Issue 2, 218-224. 